\title{
Conhecimento Especializado do Conteúdo Explicitado por Professoras que Estudam Formas Poligonais
}

\section{Specialized knowledge of Content Explained by Teachers Studying Polygonal Shapes}

\author{
Claudia Maria de Sousa Oliveira*a; Angelica da Fontoura Garcia Silva ${ }^{\text {ab }}$; Diego Fogaça Carvalho ${ }^{\mathrm{b}}$
}

\begin{abstract}
${ }^{a}$ Universidade Anhanguera de São Paulo, Programa de Pós-Graduação Stricto Sensu em Educação Matemática. SP, Brasil. ${ }^{b}$ Unopar, Programa de Pós-Graduação Stricto Sensu em Metodologias para o Ensino de Linguagens e suas Tecnologias. PR, Brasil. *E-mail: claudiamsoliv@gmail.com
\end{abstract}

\begin{abstract}
Resumo
Esta pesquisa teve o objetivo de investigar conhecimentos profissionais explicitados por 10 professoras que cursam Psicopedagogia em uma universidade particular da Grande São Paulo que se reuniram, na própria instituição, para estudar sobre polígonos. A coleta de dados se deu por meio da recolha das respostas dadas a uma atividade e de gravações em vídeo de uma das sessões de estudo, na qual as participantes vivenciaram e discutiram a resolução da atividade. Propôs-se a elas que observassem e discutissem as características relativas aos polígonos ao analisarem figuras poligonais e não poligonais. Ball, Thames e Phelps (2008) e Serrazina (1999) foram os referenciais teóricos para analisar as informações coletadas. Antes da sessão de estudos, foi possível identificar dificuldades dos professores para definir polígonos, constituindo-se em ponto de partida para a proposição da atividade apresentada. As discussões e reflexões propostas durante a sessão favoreceram a ampliação do conhecimento especializado, do conteúdo e do ensino, uma vez que as docentes perceberam outras possibilidades de introduzir a temática que não somente, a apresentação da definição seguida da exemplificação.
\end{abstract}

Palavras-chave: Educação Matemática. Conhecimento Profissional Docente. Polígonos.

\begin{abstract}
This research aimed to investigate professional knowledge explained by 10 teachers who study Psychopedagogy at a private university in greater São Paulo who met at the institution to study polygons. Data was gathered by collecting responses given in an activity and video recordings of one of the study sessions in which participants experienced and discussed the resolution of an activity. Participants were asked to observe and discuss the characteristics related to polygons when analyzing polygonal and non-polygonal figures. Ball, Thames \& Phelps (2008) e Serrazina (1999) were the theoretical references to examine the collected information. Before the study session, it was possible to identify teachers' difficulties in defining polygons, constituting a starting point for the proposition of the activity presented here. The discussions and reflections proposed during the session analyzed here favored the expansion of specialized knowledge, as well as content and teaching, once the participants realized new possibilities to introduce the theme other than just from the presentation of definition followed by exemplification.
\end{abstract}

Keywords: Mathematical Education. Teaching Professional Knowledge. Polygons.

\section{Introdução}

Parece ser consenso a preocupação com as dificuldades encontradas no contexto brasileiro para realizar um ensino de qualidade. Dessa forma, consideramos fundamental destacar o papel do professor no desenvolvimento de processos de ensino e aprendizagem. Acreditamos ser importante olhar para os conhecimentos profissionais de professores por reconhecermos que é o educador que pode contribuir de forma decisiva para ampliar as habilidades e competências dos alunos.

Acreditamos, ainda, que possivelmente, uma formação inicial e ideal do professor seria aquela que fornece ferramentas para enfrentar os primeiros desafios inerentes a profissão. Não podemos deixar de destacar a necessidade de, no decorrer do desenvolvimento da profissionalidade docente, favorecer espaços de estudos que promovam a ampliação da base de conhecimentos para o ensino e a reflexão sobre a prática. Concordamos com Miranda (2019) quando afirma ser relevante a promoção de investigações que ocorram em ambientes formativos que busquem aprofundar conhecimentos profissionais sobre o ensino da Matemática por meio de estudos e vivências que favoreçam a reflexão sobre a prática.

Da mesma forma que Fujita e Jones (2006), Nogueira, Pavanello e Oliveira (2014) e Barros e Sampaio (2014), preocupamo-nos com conhecimentos explicitados por professores a respeito de polígonos. Os autores escoceses Fujita e Jones (2006), apoiados em pesquisas anteriores, afirmam que, entre os conhecimentos matemáticos que os educadores iniciantes atuantes na Educação Básica evidenciam, há uma significativa defasagem relacionada à capacidade em definir e classificar quadriláteros. Os autores perceberam também que as dificuldades e lacunas identificadas nos conhecimentos de alunos, aparentemente, persistem em professores após o período de formação profissional. No tocante às limitações de conhecimentos de professores para o ensino dessa temática, 
notamos que os resultados de Fujita e Jones (2006) também foram observados em pesquisas brasileiras, como a de Barros e Sampaio (2014). Eles investigaram tarefas realizadas por alunas de cursos de Pedagogia e evidencia dificuldades das participantes tanto na compreensão de ideias relativas aos polígonos quanto na identificação de figuras que caracterizam regiões planas e de propriedades dos quadriláteros. Também nesse contexto, encontramos aproximações com os resultados de duas investigações - a de Fujita e Jones (2006) e a de Barros e Sampaio (2014) — que mostram lacunas no conhecimento de futuros professores que lecionarão Matemática.

Assim como esses dois estudos, Nogueira, Pavanello e Oliveira (2014), preocupam-se em investigar conhecimentos de profissionais do ensino. As autoras realizaram uma pesquisa, em um curso de formação continuada para licenciados em Matemática, com o propósito de analisar o conhecimento desses profissionais sobre a Matemática dos Anos Iniciais e "verificar os efeitos de um processo de formação continuada, em sua prática pedagógica" (Nogueira et al., 2014, p. 138). Como resultado da investigação, as autoras mostram que o conhecimento dos professores formados em Matemática era fundamentalmente procedimental. Para Nogueira et al. (2014, p.150),

Os conhecimentos dos professores se limitaram aos triângulos, quadriláteros e aos polígonos regulares, inclusive se surpreendendo com a possibilidade de um quadrilátero ser côncavo. Isto significa que a própria definição de polígono não está bem estabelecida entre eles. Mesmo quando conseguiam nomear corretamente um polígono, houve professores que não foram capazes de explicitar os critérios utilizados para este reconhecimento, ou seja, a descrição de suas propriedades

Além disso, as autoras afirmam que tais dificuldades seriam "exatamente as mesmas constatadas em nossa atuação em cursos de formação continuada para professores licenciados em Pedagogia" (Nogueira et al., 2014, p.150).

Vale destacar que neste artigo apresentamos resultados de uma pesquisa de mestrado já concluída. No que concerne à organização deste texto, apresentamos, inicialmente, as referências teóricas utilizadas na pesquisa e na análise dos dados. Em seguida, discorremos sobre os procedimentos metodológicos, a análise e a discussão dos dados obtidos. Por último, expomos nossas considerações finais.

\section{Fundamentação Teórica}

Em Ball, Thames \& Phelps (2008), buscamos pressupostos para analisar o "conhecimento matemático para o ensino". Os autores buscam o entendimento sobre os saberes do professor e sobre as formas pelas quais eles necessitam saber Matemática para usar esse conhecimento em seu ensino. A partir da investigação de práticas docentes e apoiados em Shulman (1986), apresentam categorias definidos por eles como a base de conhecimento para o ensino da Matemática, conforme o diagrama exposto na Figura 1.
Figura 1 - Categorias definidas por Ball et al. (2008) a partir da nronosta de Shulman (1986)

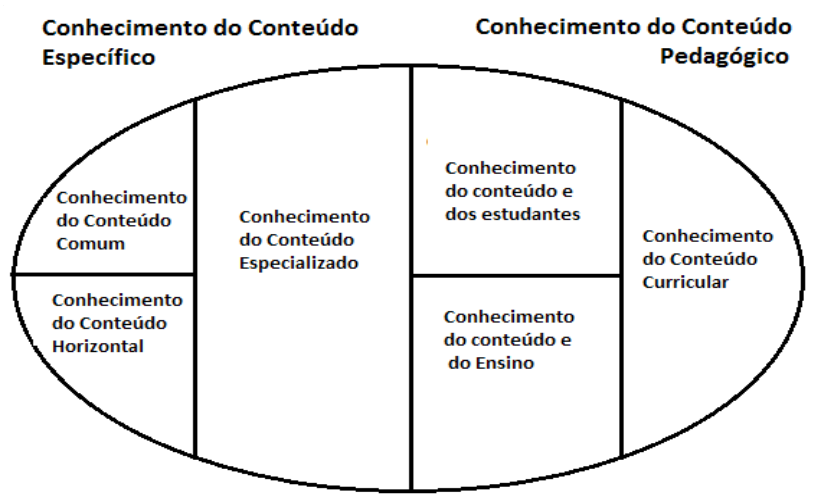

Fonte: Baseado em Ball et al. (2008, p.403).

Nesse contexto, observamos que o conhecimento do conteúdo específico foi subdividido em conhecimento do conteúdo comum, conhecimento do horizonte do conteúdo e conhecimento do conteúdo especializado. O conhecimento do conteúdo pedagógico foi subdividido em conhecimento do conteúdo e dos estudantes, conhecimento do conteúdo e do ensino, e conhecimento do conteúdo curricular. Como nesta investigação analisaremos o conhecimento do conteúdo especializado e o conhecimento do conteúdo e do ensino, iremos descrevê-los a seguir.

O segundo domínio apresentado é o conhecimento do conteúdo especializado, que se relaciona com o saber sobre a tarefa de ensinar Matemática, não envolvendo nenhuma outra atividade cotidiana ou profissional. Para Ball, Thames e Phelps (2008), ele vai além do conhecimento do conteúdo comum, ensinado para os alunos. Envolve, ainda, justificativas e formas de prover significados aos tópicos estudados e ter explicações e ilustrações para os conceitos desenvolvidos. $\mathrm{Na}$ base de conhecimentos para o ensino de um conteúdo matemático qualquer, pressupõe-se a proficiência do professor no tocante ao Conhecimento do Conteúdo e do Ensino (KCT). Para essa categoria, espera-se do professor a capacidade de escolha de exemplos e ilustrações que poderiam propiciar aos alunos a compreensão do conteúdo a ser ensinado.

Concernente à reflexão sobre a prática, iremos nos apoiar nos estudos de Serrazina (1998) ao afirmar que "quando os professores aprofundam o seu conhecimento e exploram novos materiais e novas tarefas de ensino, muitas vezes encontram surpresas que desafiam as suas crenças sobre a forma como os alunos aprendem e adquirem conhecimento matemático" (Serrazina, 1998, p.3). Para a autora, o isolamento do professor pode levá-lo a desistir de suas atribuições, uma vez que mudanças da prática carregam consigo sentimentos desconfortantes. Dessa forma, a autora afirma que o trabalho coletivo e o acolhimento gerado pelo grupo podem fortalecer reflexões.

Serrazina (1998) discute como os professores de Matemática são capazes de planejar e aplicar atividades que propiciem a seus alunos a construção de conhecimentos 
significativos dos conceitos e procedimentos matemáticos e, por consequência, possibilitem a integração e transformações de conhecimentos do próprio professor na relação com as atividades matemáticas. Sobre isso, a autora afirma:

Este processo pode ser muito estimulado pela presença de alguém que ajude os professores a refletir nas suas próprias práticas e um ambiente onde possam discutir e partilhar significados, de forma a adquirirem mais conhecimento matemático e maior confiança nas suas próprias capacidades para aprender mais matemática. (Serrazina, 1999, p. 5).

A pesquisa de Serrazina (1999) e a de Ball et al. (2008) nos apoiaram nas análises dos dados, por meio delas procuramos, nas reflexões realizadas, evidências de mudanças ocorridas na base de conhecimentos para o ensino do conceito de polígono.

Além disso, a pesquisadora, que fez parte do grupo, procurou promover situações reflexivas ao longo das atividades desenvolvidas, tanto nas etapas de investigação sobre os conhecimentos das participantes quanto na elaboração das ações que se seguiam.

Nesta pesquisa, buscamos identificar conhecimentos especializados explicitados pelas professoras a partir da vivência em uma proposta de atividade que tencionava reconhecer polígonos entre outras figuras (XXX, 2019). Cabe salientar que durante todo o processo formativo, pautarmo-nos nos estudos de Moise e Downs (1971) para discutir a definição do objeto matemático Polígonos e Polígonos Convexos. Nesse estudo, polígono é assim definido:

Seja $\mathrm{P}_{1}, \mathrm{P}_{2}, \ldots, \mathrm{P}_{\mathrm{n}}$, uma sequência de $\mathrm{n}$ pontos distintos num plano com $\mathrm{n} \geq 3$. Suponha que os $\mathrm{n}$ segmentos , ,.., , têm as seguintes propriedades:
(1) nenhum par de segmentos se intercepta a não ser nas suas extremidades.

(2) nenhum par de segmentos com extremidade comum é colinear. Então a reunião dos n segmentos é chamada polígono. (Moise \& Downs, 1971, p.473).

A partir dessa definição os autores identificam seus elementos - lados, vértice e ângulo. É importante destacar que, no excerto da investigação aqui apresentado, não discutimos tal definição, mas consideramos relevante indicar que pretendíamos, durante as outras sessões de estudo, analisar como o objeto é definido teoricamente. Nesse contexto, estávamos em busca de elementos para aprofundar a base de conhecimentos das professoras participantes a respeito dessa temática.

\section{Aspectos Metodológicos}

Esta investigação, de natureza qualitativa, foi autorizada pela Comissão de Ética do Comitê de Ética em Pesquisa do Conselho Nacional de Ética em Pesquisa (CEP/Conep), sob o número 3.089.962. Compõe uma pesquisa maior dedicada à formação de professores, desenvolvida no contexto de um grupo de estudos constituído em uma faculdade particular, situada na Grande São Paulo e realizada com quatro pedagogas concluintes do curso de especialização em Psicopedagogia, na qual a primeira autora atuava como professora. O grupo foi constituído no contraturno das aulas, e a temática a ser estudada foi escolhida coletivamente. Assim, a pesquisa de campo foi realizada com a colaboração de 4 professoras, cujas informações do perfil estão sistematizadas no Quadro 1.

Quadra 1 - Perfil das professoras participantes do grupo de estudos

\begin{tabular}{|c|c|c|c|c|c|c|c|c|}
\hline \multirow[t]{2}{*}{ Prof. } & \multirow[t]{2}{*}{ Idade } & \multicolumn{2}{|c|}{ Ed. Básica } & \multirow[t]{2}{*}{$\begin{array}{c}\text { Curso } \\
\text { Superior }\end{array}$} & \multicolumn{2}{|c|}{$\begin{array}{l}\text { Curso } \\
\text { Superior }\end{array}$} & \multirow[t]{2}{*}{$\begin{array}{c}\text { Curso } \\
\text { Superior Ano } \\
\text { de Conclusão } \\
\end{array}$} & \multirow[t]{2}{*}{$\begin{array}{c}\text { Tempo de } \\
\text { Experiência na } \\
\text { Docência } \\
\end{array}$} \\
\hline & & Publ. & Part. & & Part. & Publ. & & \\
\hline $\mathrm{S}$ & 32 & $\mathrm{X}$ & & Pedagogia & $\mathrm{X}$ & & 2017 & 1 ano e 6 meses \\
\hline $\mathrm{J}$ & 34 & $\mathrm{X}$ & & Pedagogia & $X$ & & 2017 & 1 ano e 3 meses \\
\hline $\mathrm{V}$ & 37 & $\mathrm{X}$ & & Pedagogia & $\mathrm{X}$ & & 2010 & 8 anos e 7 meses \\
\hline $\mathrm{Z}$ & 40 & $\mathrm{X}$ & & Pedagogia & $\mathrm{X}$ & & 2017 & 2 anos e 1 meses \\
\hline
\end{tabular}

Fonte: Dados da pesquisa.

Observando a tabela, é possível identificar que todas as participantes, com idades entre 30 e 40 anos, são formadas em Pedagogia, no mínimo, há 1 ano. Notamos, ainda, que as professoras não são tão experientes, 2 atuam há pouco mais de 1 ano, 1 tem 2 anos de experiência e somente 1 leciona há mais de 8 anos. Reiteramos que todas demonstraram muito interesse por nossa investigação e se ofereceram voluntariamente para participar desta pesquisa.

A pesquisa foi desenvolvida por meio da coleta de dados e ocorreu durante a segunda sessão de estudos. Tal coleta se deu ao longo da vivência em uma proposta de atividade e em uma posterior discussão em grupo.

\subsection{Atividade vivenciada e discutida no interior do grupo}

A atividade tinha o propósito, antes mesmo de discutir sobre a definição formal de polígono, de identificar, em um conjunto de figuras, quais eram poligonais. Ela faz parte do material de apoio ao Currículo ata (1998), folha XXIV, atividade n. ${ }^{\circ} 46$, "Os Polígonos", destinada a orientar professores que lecionassem para crianças de 9 anos.

Objetivávamos, por meio da análise das figuras poligonais, que as participantes discutissem sobre suas propriedades. Para desenvolver a proposta, apresentamos uma tabela com linhas e colunas na qual cada linha formava um conjunto de seis imagens, cinco com características semelhantes e uma que apresentava traços ou propriedades diferentes das demais. A 
tarefa solicitava que cada participante identificasse a figura diferente das demais e justificasse por escrito sua escolha (Figura 2).

Figura 2 - Atividade inicial - Questão 2 (Secretaria de Estado da Educação, 1998, p.188)

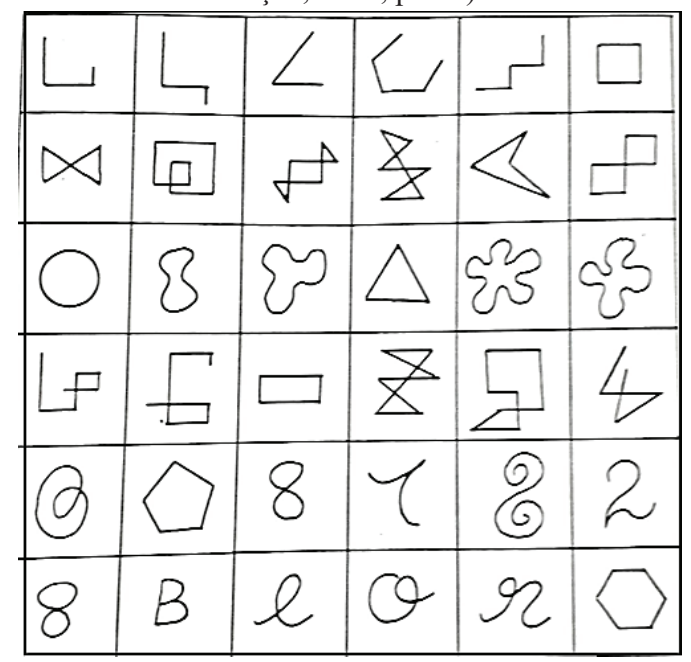

Agora que conhecemos a atividade, passemos aos dados coletados com as participantes. Eles serão apresentados na próxima seção.

\subsection{Análise e Discussão dos Dados}

Numa entrevista inicial, quando questionamos como as professoras definiriam polígonos para seus alunos, identificamos que nenhuma apresentou uma proposta de definição. Três delas — J, S e Z - afirmaram desconhecer a definição, já a professora $\mathrm{V}$ se ateve a propor encaminhamentos didáticos, uma vez que afirmou que procuraria identificar os conhecimentos prévios dos alunos e descobrir se seus discentes reconheceriam polígonos em imagens presentes no cotidiano: "Que no nosso dia a dia podemos identificar alguns [polígonos].Perguntaria quais [polígonos] eles conhecem, um conhecimento prévio da turma". Esses dados se aproximaram dos encontrados por Fujita e Jones (2006) e Pavanello e Oliveira (2014), que também observam defasagens relacionadas à capacidade em definir polígonos. Com base nessas informações, tencionamos levar uma proposta que favorecesse a discussão sobre as características relativas aos polígonos e promovesse uma vivência para introdução da temática a partir da investigação de uma situação.

Ainda no início da sessão de estudos, quando as professoras tiveram acesso à questão (Figura 2), observamos que elas se sentiam inseguras para justificar suas escolhas. A professora S, por exemplo, questionou: "Posso explicar assim: Por que as pontas se juntam? Ou por que essa figura é fechada?". Procuramos tranquilizá-la, e as demais professoras disseram que poderiam utilizar o vocabulário que melhor expressasse sua forma de pensar para realizar a escolha. Passado esse primeiro impacto, todas as professoras se empenharam em fazer as escolhas e justificá-las. Foi necessário explicar a atividade mais de uma vez, de forma individualizada para as participantes, que se mostravam inseguras na execução da tarefa.

Analisando as escolhas das docentes, observamos que as professoras $\mathrm{S}$ e $\mathrm{Z}$ indicaram o polígono de cada uma das linhas, totalizando os seis esperados (Figura 3).

Figura 3 - Atividade inicial: Questão 2, respostas das participantes

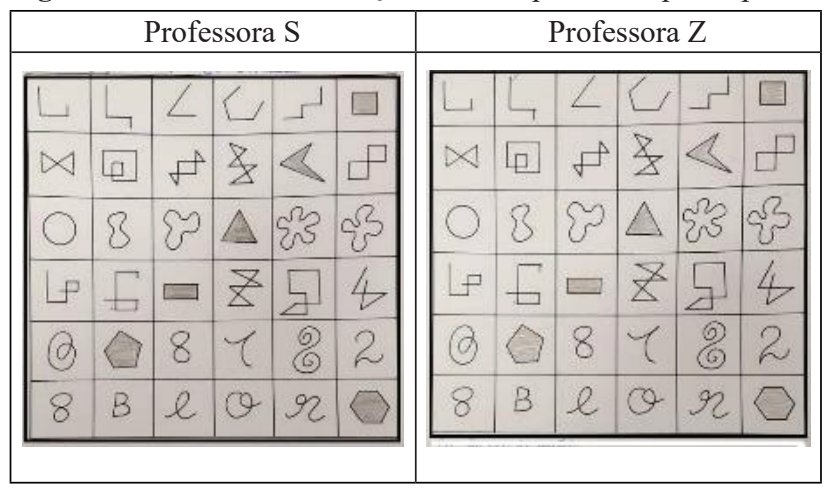

No entanto, observamos que a professora $\mathrm{J}$ indicou somente quatro figuras poligonais, e a professora $\mathrm{V}$, somente uma (Figura 4).

Figura 4 - Atividade inicial: Questão 2, respostas das participantes

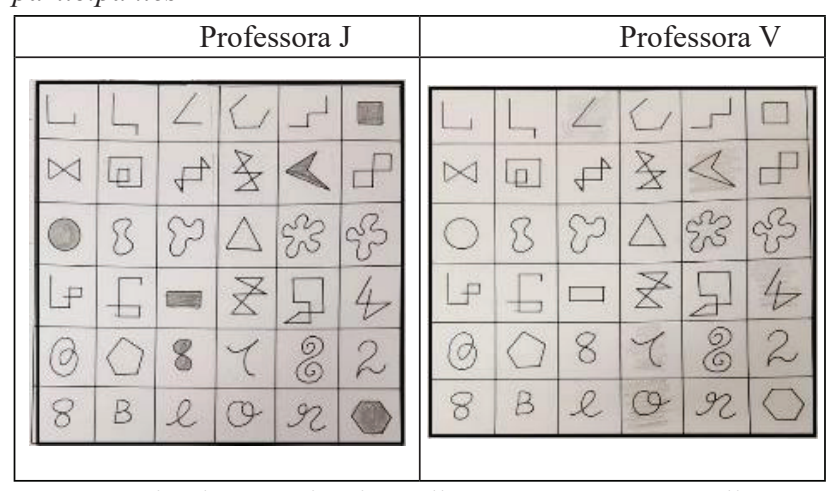

A partir desse primeiro olhar, procuramos analisar as escolhas e justificativas, linha a linha, e discutir com as professoras o ocorrido (Figura 5).

Figura 5 - Respostas à Questão 2, linha 1

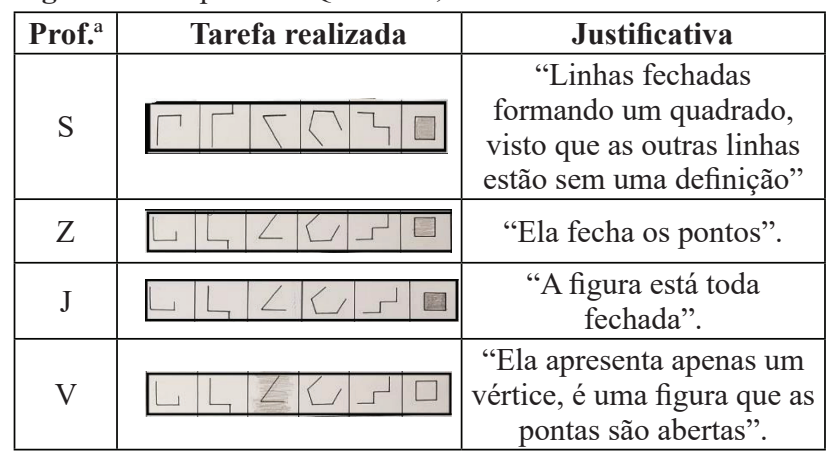

Observando as indicações e justificativas das docentes, é possível notar que três delas ( $\mathrm{S}, \mathrm{Z}$ e J) escolheram o quadrado e justificaram dizendo que essa opção era a única figura fechada. Já a professora $\mathrm{V}$ escolheu a figura que estava na terceira coluna e argumentou que essa era a única figura que "apresenta um vértice [referindo-se ao ponto que liga dois segmentos de retas] [e, além disso,] uma figura que as pontas 
são abertas".

Analisando o ocorrido, é possível observar que três professoras identificaram que o quadrado era a única figura fechada. Todavia, para a professora $\mathrm{V}$, essa não foi a característica determinante, ela justificou seu critério de escolha a partir da quantidade de vértices das figuras. Durante nossas discussões e reflexões, procuramos discutir esses critérios.

Formadora: Qual foi a figura escolhida na linha 1?

[J, S e Z dizem que escolheram o quadrado.]

V: Eu escolhi a figura com forma de nariz [referindo-se à figura localizada na terceira coluna]!

Formadora: Por que vocêfez essa escolha?

$\mathrm{V}$ : Ela apresenta apenas um vértice [apontando para a intersecção dos segmentos de reta] e também porque é uma figura que as pontas são abertas.

Formadora: Vocês concordam que essa figura é a única que apresenta esse ponto de interseção?

Z: Concordo, mas ela é aberta como as outras.

Formadora: Z, por que você escolheu a figura quadrada?

Z: Porque ela é fechada, as outras são abertas!

Formadora: Vocês concordam com a Z?

J: Todas as figuras desta linha são Abertas. Somente o quadrado é fechado. Todas concordaram com J.

Formadora: Vo que você pensa sobre isso?

V: Eu não prestei a atenção! Vi o formato de nariz, foi isso que me chamou a atenção! Mas concordo que esta não é a figura correta!

Formadora: Podemos dizer que a principal característica da figura escolhida na primeira linha seria...

O grupo definiu: Que é uma figura fechada!

(Diálogo entre as professoras e a formadora, 2019).

A definição do grupo foi registrada no quadro analisando o diálogo estabelecido entre as participantes do grupo, foi possível identificar que houve uma mudança de olhar da professora $\mathrm{V}$ para sua primeira escolha (Figura 6).

Figura 6 - Respostas à Questão 2, linha 2

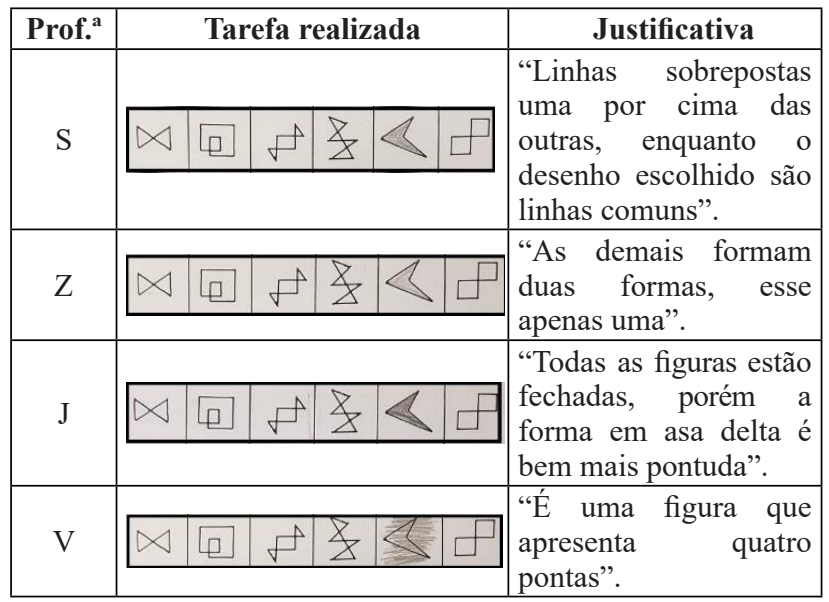

Assim como na linha 1, prosseguimos as reflexões sobre as respostas da linha 2. Diferentemente da situação anterior, no caso da figura indicada na linha 2 , todas as professoras apontaram a mesma figura como sendo a diferente.

Formadora: Qual foi a figura escolhida na linha 2?

J: Escolhi essa que parece uma asa-delta! Todas as figuras estão fechadas, porém a forma em asa-delta é bem mais pontuda!

S: Linhas sobrepostas uma por cima das outras, enquanto o desenho escolhido são linhas comuns!

$\mathrm{Z}$ : As demais formam duas formas, esse apenas uma, e as linhas dessa não se cruzam!

\section{$\mathrm{V}$ : É uma figura que apresenta quatro pontas.}

Formadora: Podemos dizer que, para essa figura, a principal característica seria ...

Z: Acho que as linhas não se cruzam, porque, nas outras figuras, as linhas estão sobrepostas, elas se cruzam!

Formadora: Vocês concordam?

[O Grupo sinalizou positivamente]

Formadora: Como fica a definição?

(Diálogo entre os professores e a formadora, 2019).

O grupo definiu, como característica da Figura 2, "As linhas não se cruzam”. É interessante observar o vocabulário utilizado pelas professoras para justificar suas escolhas. "Forma de asa-delta, pontuda, quatro pontas", como notamos na Figura 7.

Figura 7 - Respostas à Questão 2, linha 3

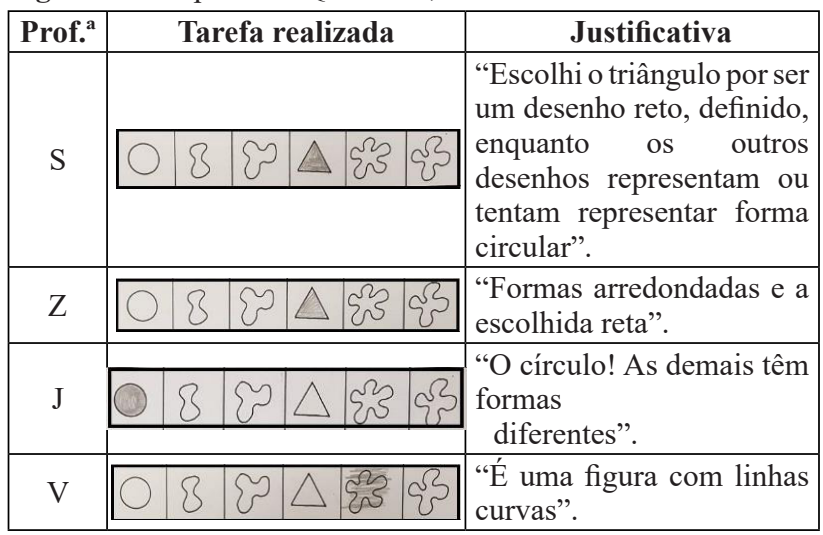

Com relação à linha 3 , as professoras $\mathrm{S}$ e $\mathrm{Z}$ escolheram as figuras triangulares e indicaram que as demais têm formas circulares ou arredondadas. Já a professora $\mathrm{J}$ escolheu o círculo, justificando que as demais têm "formas diferentes". Observamos que, para essa professora, o círculo se destaca das demais figuras, pois não classificou as demais como "formas arredondadas", assim como não notou, na figura triangular, propriedades diferentes. A professora $\mathrm{V}$ escolheu uma das figuras de linhas curvas como a figura diferente, constatamos que ela também não observou propriedades diferentes na figura triangular.

Formadora: Qual foi a figura escolhida na linha 3 e por quê?

J: O circulo, porque os demais têm formas diferentes!

S: Escolhi o triângulo por ser um desenho reto e definido, 
enquanto os outros desenhos representam ou tentam representar forma circular!

Z: Eu escolhi o triângulo também porque ele tem linhas retas, as outas não!

\section{V: É uma figura com linhas curvas!}

Formadora: Duas das colegas identificaram a mesma figura, $e$ as outras duas colegas identificaram figuras diferentes, qual vocês acreditam estar correta?

Z: Eu acho que é o triângulo, porque ele é o único com linhas retas!

$\mathrm{V}$ : Mas eu acho que é esse o meu porquê, ele tem linhas curvas!

Formadora: Observando as outras figuras, quantas têm linhas curvas ou linhas retas?

V: [Fica em silêncio observando a folha e responde:] $A h$ ! Verdade! Só essa, o triângulo tem linhas retas, é essa a diferente!

J: É, o círculo também tem curva, né, não pode ser! Era o triângulo mesmo!

\section{S: É não pode! Círculo também não pode!}

Formadora: Então como fica a definição da figura 3?

O grupo definiu: Figura de linhas retas. [E esse foi o registro no quadro.]

(Diálogo entre os professores e a formadora, 2019).

No diálogo estabelecido entre os participantes do grupo, novamente foi possível notar que houve uma mudança de olhar das participantes V e J para suas escolhas (Figura 8).

Figura 8 - Respostas à Questão 2, linha 4

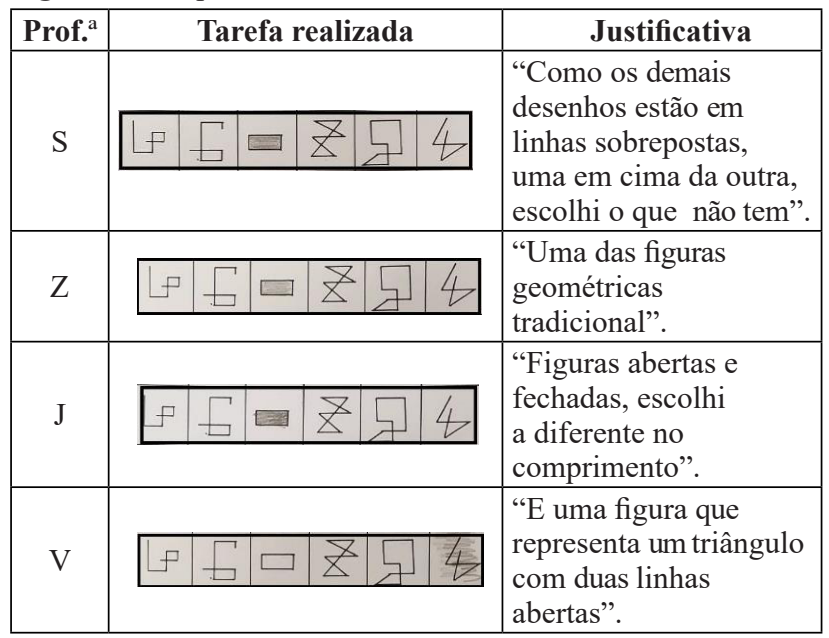

Ao analisar as respostas das professoras S, Z e J, foi possível observar que todas consideram a ausência de linhas cruzadas, classificando-a como "diferente" ao escolherem a figura retangular e, por consequência, observaram, apesar de não nomear, o número de lados e de vértices. A professora $Z$, por exemplo, categorizou-a como "figura geométrica tradicional". No entanto, a professora V, apesar de não indicar a figura esperada, selecionou uma figura que, a seu ver, representa um triângulo com "linhas abertas". Tais considerações revelam que essas docentes não demonstram reconhecer características básicas das figuras geométricas.
Formadora: Qual foi a figura escolhida na linha 4 e por quê?

J: Figuras abertas e fechadas, a escolhida é diferente no comprimento, o retângulo. Foi o comprimento que me chamou a atenção!

S: Como os demais desenhos estão em linhas sobrepostas, uma em cima da outra, escolhi a que não tem!

Z: É uma figura geométrica tradicional, uma figura conhecida!

V: É uma figura que apresenta um triângulo com duas linhas abertas.

Formadora: Vamos pensar! No conjunto de figuras desta linha, todas apresentam uma característica em comum, algo que todas têm igual, com uma exceção. Qual é esta característica?

$\mathrm{Z}$ e S: Todas as outras se cruzam, menos o retângulo!

V: Isso é verdade! Não olhei isso! Errei essa também!

$\mathrm{J}$ : Então nessa, o retângulo, também as linhas não se cruzam!

(Diálogo entre os professores e a formadora, 2019).

Assim, registramos no quadro o que foi consenso no grupo. Após a reflexão sobre as respostas, a professora $\mathrm{V}$ reavaliou sua resposta e mudou de opinião, ressignificando seu conhecimento (Figura 9).

Figura 9 - Respostas à Questão 2, linha 5

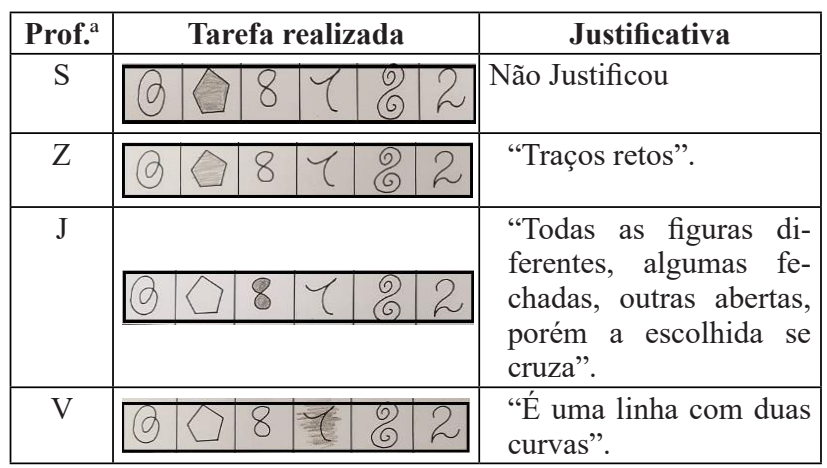

Formadora: Qual foi a figura escolhida na linha 5 e por quê?

J: Todas as figuras são diferentes, algumas fechadas, outras abertas, porém a que escolhi se cruza! Tem formato de um oito!

S: Escolhi o retângulo! Mas não é retângulo! Sei que tem outro nome, mas não me lembro! É uma figura fechada, linhas retas e não se cruzam, não sei o nome, tem muitos lados, parece com uma forma geométrica! [referindo-se ao pentágono]

\section{Z: Tem traços retos!}

V: É uma linha com duas curvas! Ah! Verdade, todas têm curvas, uma não!

$\mathrm{J}$ : É, eu não vi assim, mas tá errado! Essa aqui não tem curvas, não se cruza então é essa! [referindo-se ao pentágono] Então, pra essa fica assim: É fechada, tem linhas retas que não se cruzam!

Formadora: Todas concordam?

(Diálogo entre os professores e a formadora, 2019) 
Em comum acordo, rescrevemos essas propriedades, como vemos na Figura 10.

Figura 10 - Respostas à Questão 2 - linha 6

\begin{tabular}{|c|c|c|c|c|c|c|}
\hline Prof. $^{a}$ & \multicolumn{5}{|c|}{ Tarefa realizada } & Justificativa \\
\hline S & 8 & $B$ & $\ell$ & $\theta$ & $r$ & $\begin{array}{l}\text { "Escolhi a figura fechada, } \\
\text { linhas retas". }\end{array}$ \\
\hline Z & 8 & $B$ & $l$ & $\theta$ & $r$ & $\begin{array}{l}\text { "Os demais são letras e } \\
\text { números e a escolhida, } \\
\text { forma". }\end{array}$ \\
\hline $\mathrm{J}$ & 8 & $B$ & $\ell$ & $\theta$ & $\Omega$ & $\begin{array}{l}\text { "A única que é quadrada e } \\
\text { arredondada". }\end{array}$ \\
\hline V & 8 & B & $e$ & $\theta$ & $r 0$ & $\begin{array}{l}\text { "É uma linha com círculo } \\
\text { oval com uma linha mais } \\
\text { comprida". }\end{array}$ \\
\hline
\end{tabular}

Formadora: Qual foi a figura escolhida na linha 6 e por quê?

J: A única que é quadrada e arredondada! [referindo-se ao hexágono]

S: Eu escolhi a figura fechada, de linhas retas!

$\mathrm{Z}$ : As demais são letras e números, eu escolhi a forma geométrica!

V: É uma linha com um círculo oval com uma linha mais comprida, mas eu já sei que não está certo!

Formadora: Por que você escolheu esta figura?

V: Porque ela se cruza de verdade, aqui na curva do O e tem duas pontas!

[referindo-se à letra cursiva $\mathrm{O}]$

Formadora: As outras figuras não apresentam linhas que se cruzam?

V: Sim, mas, é, tá errado! Olhando agora todas têm curvas, se cruzam, menos essa que tem linhas retas e é fechada [referindo-se ao hexágono]!

(Diálogo entre os professores e a formadora, 2019)

Definimos, então, que as propriedades eram "figuras fechadas, compostas por segmentos retas que não se cruzam". Nesse momento, retornamos à lista de propriedades, desde a Figura 1, e lemos, uma a uma, todas as propriedades das figuras destacadas em cada linha. Com isso, o grupo percebeu que as propriedades se repetiam em cada uma das figuras.

Z: As figuras são diferentes na forma, mas têm características iguais, são todas fechadas, com linhas retas que não se cruzam!

[O grupo concordou.]

Formadora: Poderíamos afirmar que, sendo figuras diferentes que possuem características semelhantes, poderiam se enquadrar um uma categoria? Qual seria?

\section{V: De formas geométricas!}

Formadora: Formas geométricas é mais abrangente, envolve um grupo de figuras bastante variado! Essas figuras que identificamos hoje fazem parte de um grupo mais especifico. Qual seria este grupo?

\section{Z: Tangram?}

Formadora: "Tangram é um jogo! Elas estão lá, mas será que tem todas lá? Pensem nas aulas de geometria.

\section{S: Poligonos?}

Z: Mas eu descobri que polígonos e formas geométricas é a mesma coisa!

J: Eu acho que não! Polígonos é uma categoria, não é?!

Formadora: Sim, o que acabamos de fazer foi identificar algumas das propriedades dos polígonos regulares.

(Diálogo entre os professores e a formadora, 2019)

Nesse primeiro momento, foi possível identificar que nenhuma das participantes observou os ângulos das figuras e, apesar de a professora $\mathrm{V}$ ter falado em vértice, não ficou claro seu conhecimento a esse respeito. Ela não reconheceu nenhum dos polígonos da tarefa. Notemos que o grupo identificou que as figuras eram fechadas, uma vez que eram formadas por segmentos de reta (lados) e que cada segmento de reta era interceptado exatamente por outros dois segmentos em seus extremos. Nesse sentido, tínhamos elementos para iniciar a reflexão sobre a definição formal apresentada por Moise e Downs (1971), a qual seria retomada em outra sessão; pretendíamos, com isso, aprofundar o conhecimento sobre a definição de polígono e elencar seus elementos. Todavia, como intencionávamos, nessa sessão, aprofundar discussões sobre questões didáticas relativas ao ensino da Geometria a partir da experiência vivenciada apresentamos para o grupo, ao final da sessão, o material utilizado como referência bibliográfica nessa tarefa, mostramos a atividade e a classificação etária, um desafio para crianças de 9 anos.

O grupo ficou bastante surpreso, já que não foi considerada uma tarefa fácil.

\section{V: Nossa! Eu não sei nada!}

Z: Tenho que aprender tudo de Matemática novamente, ou eu esqueci, ou não aprendi!

$\mathrm{S}$ : Acho que nós, pedagogas, não sabemos Matemática, essa atividade não foi fácil pra mim, eu não saberia trabalhar com crianças de 9 anos, não sei nem nomear uma forma diferente de círculo, quadrado, triângulo e retângulo, tem essas duas aqui que eu não sei o nome!

J: É, sei que tem uma que é trapézio, tem losango, hexágono e outra que é pentágono, acho que é uma dessas, mas não sei qual é! Tá vendo, tem muita coisa que eu não sei!

S: Nós não sabemos!

Formadora: Mas vocês acham que, para desenvolver essa tarefa, era preciso conhecer a definição?

Todas: Não.

Z: É verdade, nós não sabiamos, mas encontramos as características e também observei que fizemos o contrário do que eu via na escola, nós exploramos as figuras para depois definir o que era polígonos.

Formadora: Vocês concordam?

Todas: Sim

(Diálogo entre as professoras e a formadora, 2019)

Analisando as respostas atribuídas pelas professoras participantes, interpretamos que, inicialmente, elas apresentam dificuldades em definir polígonos. Contudo, observamos que, ao longo das discussões e reflexões geradas no grupo, favorecemos a ressignificação desses conhecimentos, já que, 
ao final das discussões, foi possível ao grupo identificar e nomear propriedades dos polígonos e reconhecer alguns de seus elementos. O grupo parecia perceber que realizamos o caminho inverso da proposta apresentada, uma vez que optamos por partir da observação para registrar e depois identificar as propriedades das figuras, e usualmente se apresenta o conceito, as propriedades e, por último, o exemplo. As participantes relataram que a experiência vivenciada nessa atividade foi significativa, pois foi diferenciada das anteriores com o ensino dessa temática.

\section{Algumas Considerações}

Ao final, a partir da vivência e discussão da atividade, o grupo conseguiu descrever, mesmo que ainda sem muita formalidade, características relativas aos polígonos. Também percebeu outras possibilidades de introduzir a temática que não somente a partir da apresentação da definição seguida da exemplificação.

Essa (re)significação de conhecimentos se deu a partir da vivência em uma proposta exploratória, a qual procurava direcionar o olhar dos professores para a identificação de algumas propriedades dos polígonos. Constatamos que tais propriedades foram retomadas e discutidas; nesse sentido, acreditamos que as relações que as participantes estabeleciam com o objeto de estudo, acrescidas das reflexões coletivas, favoreceram tal (re)significação.

Ao final, o grupo inferiu que a ampliação de seu conhecimento matemático — especializado do conteúdo - pode desempenhar um papel importante na qualidade de sua prática docente. Ela permitirá, por exemplo, aprimorar a capacidade de reformular até mesmo os procedimentos didáticos de abordar novos conceitos - conhecimento do conteúdo e do ensino.

\section{Referências}

Ball, D. L., Thames, M. H., \& Phelps, G. (2008). Content Knowledge for Teaching: what makes it special? Journal of Teacher Education, 59(1), 389407.

Barros, R. M. O., \& Sampaio, H. R. (2014). O conhecimento matemático sobre os descritores "Espaço e Forma" de licenciandos em um curso de Pedagogia na modalidade a distância: resultados parciais. Revista Paranaense de Educação Matemática, 3(4), 203-222.

Fujita, T., \& Jones, K. (2006). Primary trainee teachers' understanding of basic geometrical figures in Scotland. In J. Novotná, H. Moraová, M. Krátká \& N. Stehlíková (eds.), Proceedings 30th Conference of the International Group for the Psychology of Mathematics Education (PME30) (pp. 129-136). Psychology of Mathematics Education. https://eprints.soton.ac.uk/41247/

Miranda, M. S. (2019). Escola como espaço de (re)significação de conhecimentos matemáticos para o ensino: a constituição de um grupo que estuda o currículo e investiga a própria prática [Tese de doutorado]. Universidade Anhanguera de São Paulo.

Moise, E. E., \& Downs, F. L. (1971). Geometria Moderna. São Paulo: Edgar Blucher.

Nogueira, C.M.I. , Pavanello, R.G.\& Oliveira, L.A. (2014). Uma experiência de formação continuada de professores licenciados sobre a matemática dos anos iniciais do ensino fundamental. Revista Paranaense de Educação Matemática. Campo Mourão, 3 (4), 138-160.

Oliveira, C.M.S. (2019). Formação de Professores para Educação Infantil: uma investigação acerca do ensino de formas geométricas [Dissertação de Mestrado]. Universidade Anhanguera de São Paulo.

São Paulo. (1998). Atividades Matemáticas $3^{\circ}$ série Ensino Fundamental São Paulo: SE/CENP,

Serrazina, L. (1999). Reflexão, conhecimento e práticas lectivas em matemática num contexto de reforma curricular no $1^{\circ}$ ciclo. Quadrante, 9, 139-167. 